\title{
Deaths and years of life lost due to suboptimal breast-feeding among children in the developing world: a global ecological risk assessment
}

\author{
Jeremy A Laver ${ }^{1, *}$, Ana Pilar Betrán ${ }^{2}$, Aluísio JD Barros ${ }^{3}$ and Mercedes de Onís ${ }^{4}$ \\ 'Department of Health Systems Financing, Expenditure and Resource Allocation, World Health Organization, 1211 \\ Geneva 27, Switzerland: ${ }^{2}$ Department of Making Pregnancy Safer, World Health Organization, Geneva, \\ Switzerland: ${ }^{3}$ Department of Social Medicine, Federal University of Pelotas, CP 464 - 96001-970, Pelotas, Brazil: \\ ${ }^{4}$ Department of Nutrition for Health and Development, World Health Organization, Geneva, Switzerland
}

Submitted 16 December 2004: Accepted 26 0ctober 2005

\begin{abstract}
Objective: We estimate attributable fractions, deaths and years of life lost among infants and children $\leq 2$ years of age due to suboptimal breast-feeding in developing countries.

Design: We compare actual practices to a minimum exposure pattern consisting of exclusive breast-feeding for infants $\leq 6$ months of age and continued breast-feeding for older infants and children $\leq 2$ years of age. For infants, we consider deaths due to diarrhoeal disease and lower respiratory tract infections, and deaths due to all causes are considered in the second year of life. Outcome measures are attributable fractions, deaths, years of life lost and offsetting deaths potentially caused by mother-to-child transmission of HIV through breast-feeding.

Setting: Developing countries.

Subjects: Infants and children $\leq 2$ years of age.

Results: Attributable fractions for deaths due to diarrhoeal disease and lower respiratory tract infections are 55\% and 53\%, respectively, for the first six months of infancy, 20\% and 18\% for the second six months, and are $20 \%$ for all-cause deaths in the second year of life. Globally, as many as 1.45 million lives (117 million years of life) are lost due to suboptimal breast-feeding in developing countries. Offsetting deaths caused by mother-to-child transmission of HIV through breast-feeding could be as high as 242000 (18.8 million years of life lost) if relevant World Health Organization recommendations are not followed.

Conclusions: The size of the gap between current practice and recommendations is striking when one considers breast-feeding involves no out-of-pocket costs, that there exists universal consensus on best practices, and that implementing current international recommendations could potentially save 1.45 million children's lives each year.
\end{abstract}

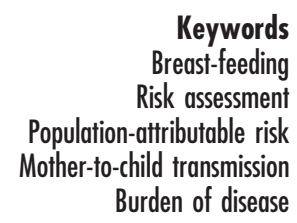

Keywords

Breast-feeding Risk assessment

Population-attributable risk Burden of disease

\section{Recent work on major global risk factors}

In 2002, the World Health Organization (WHO) highlighted the public health importance of major global risk factors for burden of disease ${ }^{1}$. Modifiable childhood nutritional risk factors such as underweight (3.75 million deaths) and deficiency of zinc (789000 deaths), vitamin A (778000 deaths) and iron (841 000 deaths) were estimated to be responsible for over 6 million childhood deaths per year. Environmental risk factors such as unsafe water, sanitation and hygiene, whose effects fall overwhelmingly on children, were estimated to be responsible for another 1.73 million deaths per year.

Although WHO did not analyse suboptimal breastfeeding, other recent analyses of causes of childhood death have qualified it as one of 'the most powerful shared risk factors ${ }^{2}$ and estimated that 1.3 million deaths could be prevented in 42 high-mortality countries by increased levels of breast-feeding among infants ${ }^{3}$. That work, by the Bellagio Child Survival Group, suggests that suboptimal breast-feeding is a childhood risk factor of the same magnitude as the other major nutritional and environmental risk factors studied by the WHO Collaborating Group $^{1,4,5}$.

On a number of technical grounds, the present work extends that published by the Bellagio group: we use published estimates of exposure for the entire developing world (135 countries) ${ }^{6}$, we apply estimates of risk consistent with current international infant feeding recommendations and, consistent with best available evidence ${ }^{7}$, we assess the effect of suboptimal 
breast-feeding throughout the second year of life. Finally, we present a detailed account of methods, assumptions and data sources.

\section{Policy background}

Excluding neonatal disorders, the most important causes of childhood deaths in developing countries are lower respiratory tract infections and diarrhoea ${ }^{2}$. It has been long understood that breast-feeding reduces not only the incidence of these diseases but also their severity and duration $^{8-11}$.

Recent debate has focused on the optimal duration of exclusive breast-feeding in infancy and in 1999 WHO commissioned a systematic review of evidence ${ }^{12}$, following which the World Health Assembly voted in 2001 to recommend exclusive breast-feeding for the first six months of life as a global public health recommendation ${ }^{13}$. On the basis of the best available evidence, therefore, current international consensus holds that optimal breastfeeding practice for infants and young children consists of exclusive breast-feeding for the first six months of life with continued breast-feeding up to 2 years of age and beyond ${ }^{14}$.

Nevertheless, breast-feeding for more than 1 year has been estimated to pose a $10-20 \%$ risk of HIV transmission in children of infected mothers ${ }^{15}$. Since the risk of HIV transmission clearly needs to be balanced against other risks faced by infants and children, WHO currently states that 'when replacement feeding is acceptable, feasible, affordable, sustainable and safe, avoidance of all breastfeeding by HIV-positive women is recommended; otherwise, exclusive breastfeeding is recommended during the first months of life'; WHO emphasizes, however, 'that those who choose other options should be encouraged to use them free from commercial influences, ${ }^{15,16}$.

\section{Methods}

\section{Design}

Using the method of population-attributable risk ${ }^{17}$, we report estimates of attributable fractions, deaths and years of life lost due to suboptimal breast-feeding among children in the developing world. Population-attributable risk measures the proportion of an outcome potentially avertable through reduced exposure to a risk factor. The outcomes considered here are childhood deaths due to diarrhoeal disease and lower respiratory tract infections in 12 global sub-regions; the corresponding risk factor is suboptimal breast-feeding.

Reduced exposure is defined here as a counterfactual distribution of childhood breast-feeding defined with reference to current international recommendations ${ }^{13}$. As recommendations distinguish children $0-5,6-11$ and $12-$ 23 months of age, all our analyses are stratified for these age groups. The counterfactual distribution constitutes the minimum level of exposure that is in principle possible; such a reference distribution has been termed 'theoretical minimum exposure ${ }^{17}$. We use the term 'suboptimal breast-feeding' throughout to refer to practices inconsistent with this defined minimum exposure distribution.

Estimates of population-attributable risk require information on current exposure status and the relative risk of the studied outcomes in the exposed group. Our exposure estimates were derived from a comprehensive review of breast-feeding patterns obtained from nationally representative data sources in the developing world. Calculation methods and validation procedures have been described elsewhere ${ }^{6}$. Our estimates of relative risk were derived from a reanalysis of data identified through a review of suitable epidemiological studies; the studies, as well as the analysis methods used to derive and validate our risk estimates, are described more fully below.

All outcome estimates refer to 2000, the year of the most recent comprehensive review of the global burden of disease, our source for data on deaths and years of life lost. Estimates of population-attributable risk are multiplied by total numbers of deaths and years of life lost due to diarrhoeal disease and lower respiratory tract infections to yield estimates of attributable deaths and attributable years of life lost.

\section{Risk of suboptimal breast-feeding}

\section{Current knowledge}

In 2000, the WHO Collaborative Study Team published a systematic review of the risk of death attributable to suboptimal breast-feeding ${ }^{7}$. For the purposes of an assessment such as the one presented here, a major limitation of that study was that pooled analysis was possible only in terms of aggregate causes of death (e.g. all infections) and only for the dichotomous categories 'any' versus 'no' breast-feeding. Moreover, no pooled estimate was published for suboptimal breast-feeding in the second year of life.

\section{Risk categories}

For infants aged $\leq 6$ months, theoretical minimum risk is defined as 'exclusive breast-feeding'. In conformity with available exposure data ${ }^{6}$, we define two increased risk categories, 'partial breast-feeding' and 'no breast-feeding', resulting in a polytomous minimum risk distribution for this age group. For infants $>6$ months of age and for children $\leq 2$ years of age, theoretical minimum risk is defined as 'continued breast-feeding', with 'no breastfeeding' as the sole increased risk category ${ }^{6}$.

\section{Risk data}

When the WHO collaborative meta-analysis was published ${ }^{7}$, only one study with data for young infants in terms of polytomous exposure categories had been identified: a case-control study performed a number of years ago in 
Brazil $^{9}$. A recent cohort study in Bangladesh ${ }^{11}$ has since been published, also with polytomous exposure data. Each study presents certain limitations for the present purposes. While the Brazilian study characterised its reference group in terms of 'predominant breast-feeding' rather than exclusive breast-feeding, the study performed in Bangladesh enrolled virtually no infants in the no breast-feeding category. Furthermore, the small number of deaths recorded in the Bangladesh study severely limited its power to estimate mortality risk for infants $>6$ months of age.

\section{Risk model}

For use in the present study, risk data, consisting of observations of exposure and outcomes in infant and child populations, require aggregation in terms of the age groups and outcomes defined here as well as transformation, by means of a mathematical structure representing the relationships in this information, into summary estimates of risk.

For the two infant age groups, reanalysis of the Brazilian data affected the age distribution in the sample, and it was necessary to analyse cases and controls irrespective of matching. Although ignoring matching can bias the association only towards the hypothesis of no effect ${ }^{18}$, exploratory comparisons showed that estimates of risk were reduced only slightly.

We used maximum-likelihood estimation of a logistic regression model implemented with the Stata procedure LOGIT. Selection of covariates was facilitated with a hierarchical model embodying a particular realisation of a distal-proximal causal web. A model with all variables at the top (most distal) level was fit, and variables with $P$-values greater than 0.20 were removed, one at a time, starting with the highest $P$-value, until all remaining variables had $P$-values less than 0.20 . The procedure was repeated for subsequent (more proximal) levels, keeping variables retained in previous levels irrespective of their $P$-values in subsequent regressions.

For the second year of life, five previous studies contained sufficient information to compute the risk of no breast-feeding on all-cause mortality ${ }^{7}$, and we used those data to compute a variance-weighted pooled mean of allcause mortality risk for children $>1$ and $\leq 2$ years of age using the Stata procedure METAN ${ }^{19}$.

\section{External validation}

Risk estimates were compared where possible with those from other studies and settings to ensure that they were reasonably consistent with other data and could therefore be applied across the diverse settings studied here. We made detailed comparisons, in polytomous terms, to appropriately reanalysed data from the study in Bangladesh and in dichotomous terms to the two other datasets ${ }^{20,21}$ with information on suboptimal breast-feeding and fatal outcomes in infants identified by the WHO collaborative meta-analysis.

\section{Outcomes}

For infants, only deaths due to diarrhoeal disease and lower respiratory tract infections are considered, but for children $\leq 2$ years of age, deaths due to all causes are included. The corresponding outcomes we derive are attributable fractions, attributable deaths and attributable years of life lost. An upper bound on deaths potentially caused by mother-to-child transmission of HIV through breast-feeding is estimated for 32 high-prevalence countries in the developing world. All estimates are reported for developing countries by United Nations subregion $^{22}$.

We use WHO figures for cause-specific deaths and years of life lost in 2000, which are estimated subject to a variety of internal and external validity constraints ${ }^{23,24}$ for the world and a set of defined epidemiological sub-regions ${ }^{25}$. WHO cause-specific death estimates are reported, by sex, for infants ( $\leq 1$ year of age) and other children ( $>1$ and $\leq 5$ years of age) and six other age groups of varying width; estimates of all-cause deaths are reported, by sex, for infants, other children and successive 5-year age groups $^{26}$.

\section{Age distribution of infant outcomes}

As breast-feeding recommendations distinguish children $0-5,6-11$ and $12-23$ months of age ${ }^{13}$, it was necessary to estimate the proportion of cause-specific or all-cause deaths occurring in various age subgroups. We used published data on the age distribution of deaths due to diarrhoeal disease and lower respiratory tract infections among children ${ }^{27}$ to estimate a linear relationship between the logarithm of childhood mortality odds and age for the relevant cause categories (Fig. 1). The estimated slope

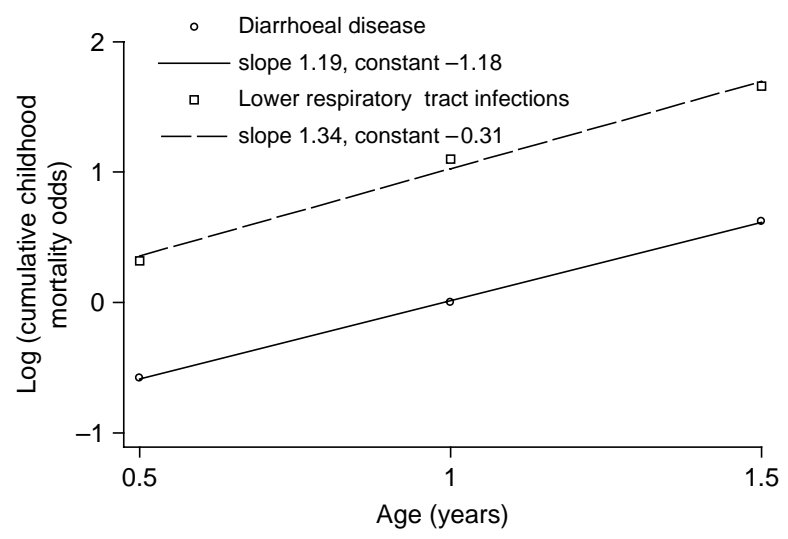

Fig. 1 Linear relationship between the logarithm of cumulative childhood mortality odds and age for selected causes. Circles (diarrhoeal disease) and squares (lower respiratory tract infections) show pooled data points ${ }^{27}$; solid and dashed lines show the estimated relationship. Estimated parameter values reported in the figure 
determines the age distribution of cause-specific deaths and the constant, the overall level of risk in the published data.

To apply this relationship to the sub-regions defined here, we assumed that the age distribution of deaths remains the same across regions but that the level of risk is context-specific. Accordingly, the estimated relationships were calibrated, by changing the constant, to fit WHO estimates of cause- and sex-specific deaths occurring by 1 year of age for each sub-region. The calibrated relationship was then used to predict sub-region-specific deaths by 6 months of age. The resulting estimates (predicted) are shown in Fig. 2 by cause and sex, along with the reported WHO estimates (observed) for comparison. We assumed that the sub-regional age distributions of years of life lost by 6 months of age were the same as those we estimated for deaths.

A similar procedure was used to obtain estimates of the proportion of childhood mortality occurring by the end of the second year of life. Here, though, we used estimated all-cause mortality risk at 1 and 5 years of age obtained from each country's life table ${ }^{26}$ and simply interpolated, on the odds scale, values for the second year of life.
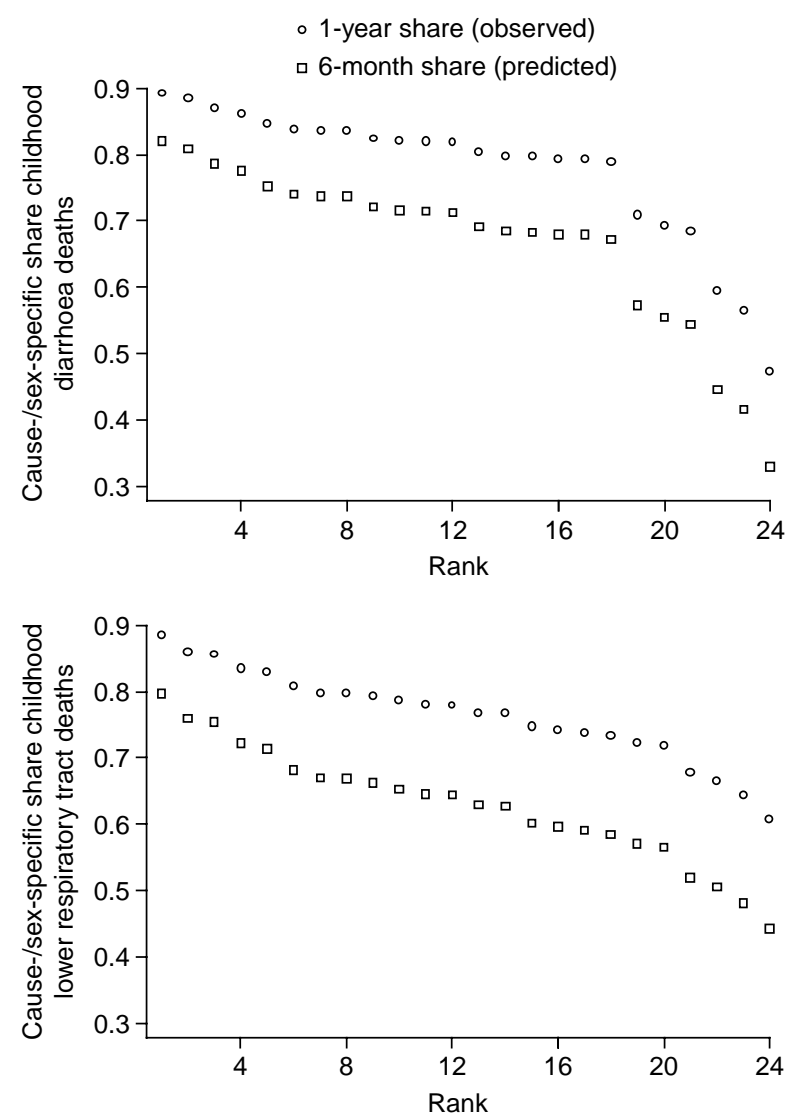

Fig. 2 Share of childhood deaths (diarrhoeal disease, upper panel; lower respiratory tract infections, lower panel). Observed (circles, 1 year) and predicted (squares, 6 month) cause- and sexspecific shares by sub-region, by rank

\section{Offsetting outcomes}

Since, for HIV-positive mothers, breast-feeding can result in transmission of HIV infection to the infant, international recommendations take into account the need to assess competing risks. As a shorthand locution, we use the term 'offsetting outcomes' throughout to denote the expected number of childhood deaths or years of life lost that would be caused by HIV-positive mothers were they to breastfeed their children at the same counterfactual rate as nonHIV-positive mothers. It is important to distinguish this artificial concept of 'offsetting deaths' (based on an assumption of breast-feeding without regard to HIV status and, therefore, in a manner inconsistent with international recommendations) from deaths that might potentially be caused as a result of the vertical transmission of HIV infection through full compliance with international breast-feeding recommendations, which specifically require a judgement concerning the balance of risk. 'Offsetting deaths' as used here thus refers to theoretical deaths that would be attributable to breast-feeding by HIVpositive mothers were they to breast-feed fully but without regard to individual- and setting-specific factors. With such 'indiscriminate' breast-feeding (i.e. without considering individual- and setting-specific factors), 'offsetting outcomes' would reduce the population benefit achievable by breast-feeding because some of the breast-fed children will die from AIDS. While a number of offsetting deaths of children of HIV-positive mothers might be unavoidable even taking into account individual- and setting-specific factors, logically, such deaths must always be fewer than those attributable to so-called indiscriminate breastfeeding by HIV-positive mothers. We estimate here the offsetting outcomes of indiscriminate breast-feeding as an upper bound on the potential harms of breast-feeding by HIV-positive mothers.

We analysed offsetting deaths in 32 high-prevalence countries (footnote, Table 6). The population at risk for mother-to-child transmission through breast-feeding was assumed to be the sub-region's infant population, and we assumed independence in the probabilities of a mother being HIV-positive ${ }^{28}$, having a live-born child survive the neonatal period and breast-feeding her child for at least 1 year. The probability of HIV transmission for children of infected mothers who breast-feed for at least 1 year was assumed to be $15 \%{ }^{15}$ and homogeneous across breastfeeding categories. The probability of mothers breastfeeding for at least 1 year was calculated as the complement of the no breast-feeding rate among infants ${ }^{6}$. We assumed that all infants becoming HIV-positive through breast-feeding die at exactly 5 years of age ${ }^{29}$.

\section{Results}

\section{Risk of suboptimal breast-feeding}

Table 1 shows a comparison, by exposure status and cause of death, of adjusted and crude estimates of risk for infants 
Table 1 Crude and adjusted* odds ratios (OR) and 95\% confidence intervals $(\mathrm{Cl})$ of infant mortality due to suboptimal breast-feeding, by cause of death and exposure category. Estimates obtained from reanalysis of data from the study reported in reference 9

\begin{tabular}{|c|c|c|c|}
\hline Age group/cause of death & $\begin{array}{l}\text { Suboptimal } \\
\text { breast-feeding } \\
\text { category }\end{array}$ & $\begin{array}{l}\text { OR, crude estimate } \\
\qquad(95 \% \mathrm{Cl})\end{array}$ & $\begin{array}{l}\text { OR, adjusted } \\
\text { estimate } \\
(95 \% \mathrm{Cl})\end{array}$ \\
\hline \multicolumn{4}{|l|}{$0-5$ months } \\
\hline Diarrhoeal disease & Partial & $3.9(2.0-7.7)$ & $2.4(1.1-5.2)$ \\
\hline Diarrhoeal disease & No & $8.1(4.6-14.5)$ & $7.3(3.7-14.4)$ \\
\hline Lower respiratory tract infections & Partial & $3.2(1.6-6.4)$ & $2.8(1.4-5.8)$ \\
\hline Lower respiratory tract infections & No & $5.6(3.1-10.0)$ & $4.7(2.4-9.1)$ \\
\hline \multicolumn{4}{|l|}{$6-11$ months } \\
\hline Diarrhoeal disease & No & $2.2(1.0-4.5)$ & $2.5(1.1-5.7)$ \\
\hline Lower respiratory tract infections & No & $2.3(0.9-5.7)$ & $2.8(1.0-7.7)$ \\
\hline
\end{tabular}

*Covariates controlled for were father living in the same household, income per capita, infant's age in months, number of previous pregnancies, mother's age in years, birth weight in grams (lower respiratory tract infections, 0-5 months); mother's education in years, mother's ethnicity, infant's age in months, household has flush toilet, birth interval in months, mother's age in years, birth weight in grams, hospital birth, delivery by Caesarian section, number of antenatal visits (diarrhoeal disease, $0-5$ months); mother's education in years, household head employed, infant's age in months, birth weight in grams, low Apgar score at birth (lower respiratory infections, 6-11 months); and income per capita by quartile, male infant, infant's age in months, household has piped water, number of persons per sleeping room, number of previous pregnancies, mother's age in years (diarrhoeal disease, 6-11 months).

from the reanalysed Brazilian data. Pooled and individual estimates of the risk of no breast-feeding for deaths due to all causes during the second year of life are shown in the 'forest plot ${ }^{19}$ depicted in Fig. 3.

\section{External validation}

To validate the polytomous estimates for infants, data from the studies in Brazil and Bangladesh were tabulated on a comparable basis and reanalysed; reanalysis for Bangladesh was possible only for infants aged $\leq 6$ months (S Arifeen, personal communication). After adjusting for a similar set of covariates (footnote, Table 1), levels of risk in the two studies are similar and show overlapping confidence intervals (Table 2).

Figure 4 compares age-specific levels of risk for deaths due to infectious diseases found in Brazil with those in each of the other two studies (Philippines ${ }^{20}$ and

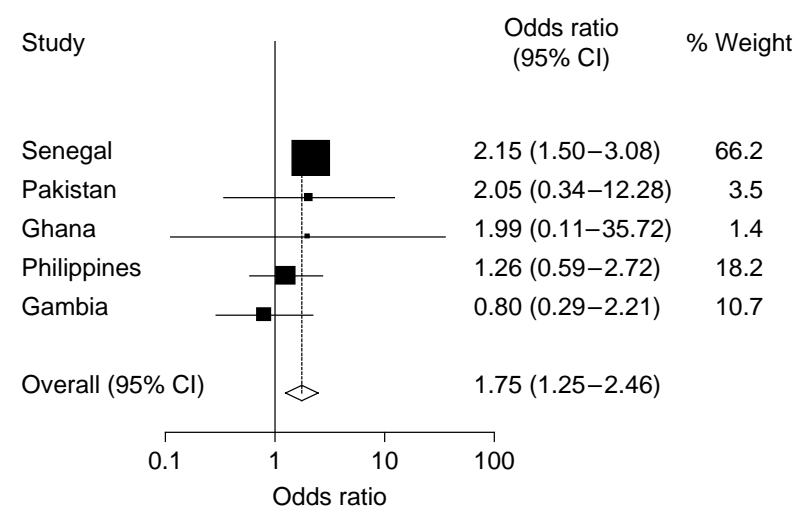

Fig. 3 Risk estimates for no breast-feeding versus continued breast-feeding during the second year of childhood (all causes of death) in five different settings. Relative size of the squares indicates relative sample size (\% weight) and the diamond shows the variance-weighted mean of the squares (overall); $\mathrm{Cl}$ - confidence interval
Pakistan $^{21}$ ) where dichotomous (i.e. 'any' vs. 'no' breastfeeding) comparisons were possible. The plot suggests decreasing age-specific risk, linear in the logarithm of the odds ratio. The estimates from Brazil are consistent with those from the other settings and are generally intermediate in risk.

\section{Attributable fractions}

Attributable fractions denote the proportion of an outcome attributable to the exposure and are reported by cause in Table 3. For infants aged $\leq 6$ months, attributable fractions are highest in Latin America and the Caribbean, followed by Africa and Asia. Globally, attributable fractions for younger infants account for more than half of fatal outcomes due to the selected causes in developing countries. For older infants, attributable fractions are highest in Latin America and the Caribbean, followed by Asia and Africa. Globally, attributable fractions for older infants account for nearly one-fifth of fatal outcomes due to selected causes in developing countries. For children in the second year of life, attributable fractions are highest in Latin America and the Caribbean, followed by Africa and Asia, and globally account for one-fifth of all fatal outcomes in developing countries.

\section{Attributable deatbs}

Attributable deaths are calculated by multiplying attributable fractions by total deaths and are reported by cause in Table 4. Globally, we estimate that 1.45 million childhood deaths are attributable to suboptimal breast-feeding in developing countries. A total of $96 \%$ of all attributable infant deaths (i.e. 1.24 million deaths) occur during the first six months of life, with 168000 attributable deaths occurring during the second year of life $(12 \%$ of all 
Table 2 Comparison of polytomous risk estimates (odds ratios and 95\% confidence intervals) for infant mortality due to selected causes, by exposure category and age group. Estimates obtained from reanalysis of data from the studies reported in references 9 (Victora et al.) and 11 (Arifeen et al.)

\begin{tabular}{|c|c|c|c|c|}
\hline Cause of death, age group & Study & No breast-feeding & $\begin{array}{c}\text { Partial } \\
\text { breast-feeding }\end{array}$ & $\begin{array}{l}\text { Predominant/exclusive } \\
\text { breast-feeding }\end{array}$ \\
\hline Diarrhoeal disease, $0-5$ months $\dagger$ & Arifeen et al. & $4.2(0.5-34.3)$ & $3.6(1.6-8.1)$ & 1.0 \\
\hline Diarrhoeal disease, $0-5$ months & Victora et al. & $7.3(3.7-14.4)$ & $2.4(1.1-5.2)$ & 1.0 \\
\hline Lower respiratory tract infections, $0-5$ months & Arifeen et al. & $5.7(1.2-26.5)$ & $2.7(1.4-5.4)$ & 1.0 \\
\hline Lower respiratory tract infections, $0-5$ months & Victora et al. & $4.7(2.4-9.1)$ & $2.8(1.4-5.8)$ & 1.0 \\
\hline Diarrhoeal disease, $6-11$ monthsł & Victora et al. & $2.5(1.1-5.7)$ & 1.0 & - \\
\hline Lower respiratory tract infections, $6-11$ months $\ddagger$ & Victora et al. & $2.8(1.0-7.7)$ & 1.0 & - \\
\hline
\end{tabular}

* Reference category with predominant and exclusive breast-feeding groups pooled.

† Reanalysed hazard ratios for infants aged 0-5 months, adjusted for selected confounding variables (S Arifeen, personal communication). Confounding variables included child's age and sex; mother's age, education, height, place of birth, parity and history of previous child death; father's education; and household religion, monthly income and economic status.

$\ddagger$ Estimates for this age group could not be calculated (S Arifeen, personal communication).

attributable childhood deaths). Attributable childhood deaths are much higher in Asia (830000) and Africa (572000) than in Latin America and the Caribbean (50000), due to the effects of larger population (Asia) and higher underlying death rates (Africa and parts of Asia). Globally, attributable infant deaths due to lower respiratory tract infections are higher (685000) than those due to diarrhoeal disease (600 000), although the pattern is reversed in Latin America and the Caribbean (20 000 and 23000 deaths, respectively).

\section{Attributable years of life lost}

Attributable years of life lost are calculated by multiplying attributable fractions by total years of life lost and are reported by cause and age group in Table 5 . Globally, 117 million years of life lost are attributable to suboptimal breast-feeding among children in developing countries.

\section{Offsetting outcomes}

Offsetting deaths and offsetting years of life lost potentially caused by mother-to-child transmission of HIV through indiscriminate breast-feeding are reported in Table 6. Globally, offsetting deaths (242000) potentially amount to $17 \%$ of those attributable to suboptimal breast-feeding in the developing world, but are as high as 36\% in Africa as a whole and 48\% in Eastern Africa. In Southern Africa, however, deaths potentially caused by mother-to-child transmission of HIV through breast-feeding are three times as high as those attributable to suboptimal breast-feeding.

\section{Discussion}

\section{Comparisons}

Compared with other childhood risk factors, our estimate of childhood deaths attributable to suboptimal breastfeeding (1.45 million) is substantially lower than estimates of deaths attributable to unsafe water, sanitation

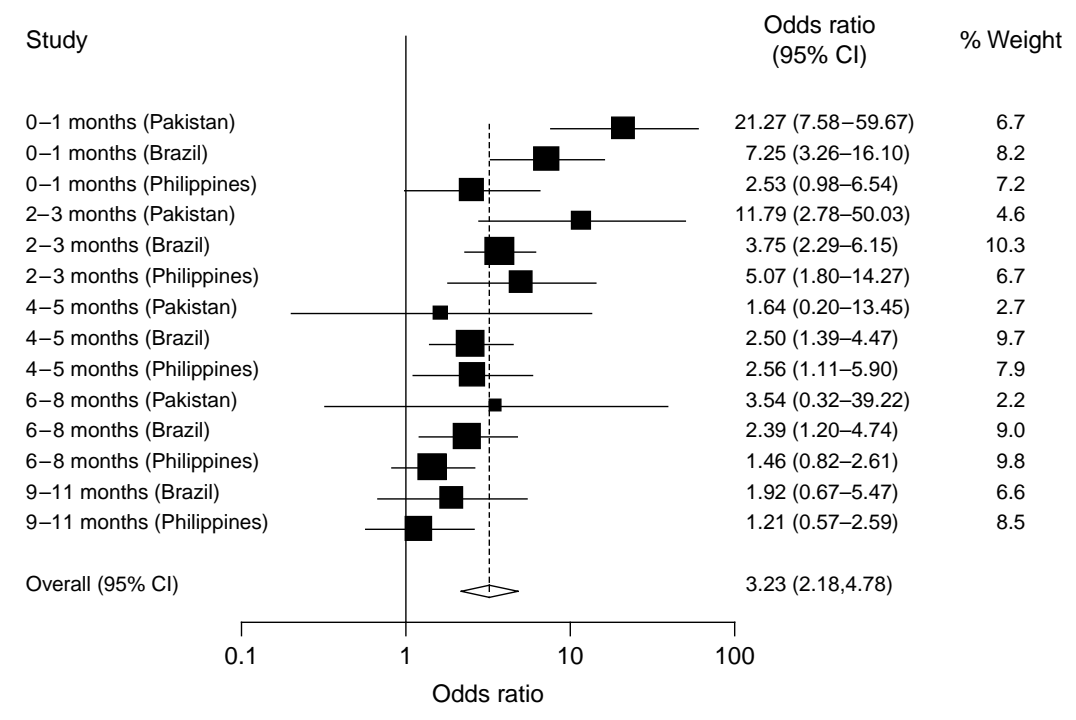

Fig. 4 Comparison of age-specific crude risk estimates for no breast-feeding versus any breast-feeding in infants (all infectious causes of death). Relative size of the squares indicates relative sample size (\% weight) and the diamond shows the variance-weighted mean of the squares (overall); $\mathrm{Cl}$ - confidence interval 
Table 3 The fraction of mortality attributable to suboptimal breast-feeding by sub-region, age group and cause of death

\begin{tabular}{|c|c|c|c|c|c|}
\hline \multirow[b]{3}{*}{ Region/sub-region } & \multicolumn{5}{|c|}{ Attributable fraction (\%) } \\
\hline & \multicolumn{2}{|c|}{$\begin{array}{c}\text { Infants }<6 \text { months } \\
\text { of age }\end{array}$} & \multicolumn{2}{|c|}{$\begin{array}{c}\text { Infants } 6-11 \text { months } \\
\text { of age }\end{array}$} & \multirow{2}{*}{$\begin{array}{c}\text { Children } \\
12-23 \text { months of age } \\
\text { All causes }\end{array}$} \\
\hline & $\mathrm{DD}$ & LRTI & $\mathrm{DD}$ & LRTI & \\
\hline Africa & 59 & 55 & 13 & 11 & 19 \\
\hline Eastern & 52 & 48 & 8 & 7 & 16 \\
\hline Middle & 59 & 54 & 6 & 5 & 16 \\
\hline Northern & 57 & 58 & 29 & 25 & 29 \\
\hline Southern & 66 & 67 & 35 & 31 & 30 \\
\hline Western & 63 & 58 & 5 & 5 & 17 \\
\hline Asia (excluding Japan) & 52 & 50 & 18 & 16 & 18 \\
\hline Eastern & 46 & 45 & 21 & 18 & $18^{*}$ \\
\hline South-Central & 52 & 48 & 11 & 9 & 14 \\
\hline South-Eastern & 56 & 55 & 30 & 26 & 23 \\
\hline Western & 63 & 62 & 34 & 30 & 33 \\
\hline Latin America and the Caribbean & 61 & 65 & 42 & 38 & 34 \\
\hline Caribbean & 61 & 65 & 42 & 38 & 34 \\
\hline Central America & 64 & 68 & 42 & 37 & 33 \\
\hline South America & 60 & 63 & 42 & 38 & 34 \\
\hline Developing countries & 55 & 53 & 20 & 18 & 20 \\
\hline
\end{tabular}

DD - diarrhoeal disease; LRTI - lower respiratory tract infection.

* Since exposure data for Eastern Asia were not available for the second year of life, the attributable fraction is the regional average attributable fraction for the age group.

and hygiene (1.73 million) and less than half (39\%) the childhood deaths attributable to underweight $(3.75$ million $)^{1}$. Fatal adult risk factors are responsible for many more deaths: for example, high blood pressure (7.14 million) and cholesterol (4.42 million) jointly account for 11.6 million cardiovascular deaths worldwide ${ }^{1}$.
However, when outcomes are measured in terms of attributable years of life lost, suboptimal breast-feeding (117 million years) ranks second only to underweight (127 million years) and is well ahead of the next largest childhood or adult risk factor studied by the WHO Collaborating Group (unsafe sex, 77 million years) ${ }^{1}$. High

Table 4 Numbers of deaths attributable to suboptimal breast-feeding, by sub-region, age group and cause of death

\begin{tabular}{|c|c|c|c|c|c|}
\hline \multirow[b]{3}{*}{ Region/sub-region } & \multicolumn{5}{|c|}{ Attributable deaths (000s) } \\
\hline & \multicolumn{2}{|c|}{$\begin{array}{c}\text { Infants }<6 \text { months } \\
\text { of age }\end{array}$} & \multicolumn{2}{|c|}{$\begin{array}{l}\text { Infants } 6-11 \text { months } \\
\text { of age }\end{array}$} & \multirow{2}{*}{$\begin{array}{c}\begin{array}{c}\text { Children } 12-23 \\
\text { months of age }\end{array} \\
\text { All causes }\end{array}$} \\
\hline & DD & LRTI & DD & LRTI & \\
\hline Africa & 197.0 & 255.7 & 7.4 & 7.1 & 104.5 \\
\hline Eastern* & 68.2 & 113.0 & 2.7 & 2.3 & 32.6 \\
\hline Middle & 30.1 & 35.8 & 1.1 & 0.6 & 18.0 \\
\hline Northern* & 17.8 & 19.6 & 1.2 & 1.7 & 6.3 \\
\hline Southern & 7.4 & 2.4 & 0.6 & 0.3 & 3.9 \\
\hline Western & 73.6 & 84.9 & 1.8 & 2.2 & 43.6 \\
\hline Asia (excluding Japan) & 359.3 & 385.5 & 12.8 & 16.4 & 56.4 \\
\hline Eastern* & 35.8 & 35.2 & 2.2 & 2.4 & $7.7 \ddagger$ \\
\hline South-Central & 265.6 & 304.3 & 6.2 & 8.8 & 33.7 \\
\hline South-Eastern & 38.2 & 23.1 & 3.2 & 3.0 & 9.0 \\
\hline Western* & 19.6 & 22.9 & 1.2 & 2.2 & 5.9 \\
\hline Latin America and the Caribbean & 20.9 & 18.1 & 2.1 & 2.3 & 7.0 \\
\hline Caribbean* & 2.9 & 2.2 & 0.2 & 0.3 & 1.3 \\
\hline Central America & 4.5 & 5.7 & 0.5 & 0.6 & 2.0 \\
\hline South America & 13.4 & 10.2 & 1.4 & 1.3 & 3.6 \\
\hline Developing countries $†$ & 577.2 & 659.3 & 22.3 & 25.8 & 167.8 \\
\hline
\end{tabular}

DD - diarrhoeal disease; LRI - lower respiratory tract infection.

${ }^{*}$ A small number of developing countries were omitted as they are not member countries of the World Health Organization and basic demographic and epidemiological data were not available: Reunion (Eastern Africa); Western Sahara (Northern Africa); Hong Kong Special Administrative Region and Macau (Eastern Asia); Gaza Strip (Western Asia); Guadeloupe, Martinique, Netherlands Antilles and Puerto Rico (Caribbean).

† The United Nations region Oceania (including developing countries Guam, Fiji, French Polynesia, New Caledonia, Papua New Guinea, Samoa, Solomon Islands and Vanuatu) was omitted as exposure data were not available for these countries.

$\ddagger$ Since exposure data for Eastern Asia were not available for the second year of life, the estimate of deaths is based on the regional average attributable fraction for the age group. 
Table 5 Years of life lost attributable to suboptimal breast-feeding, by sub-region, age group and cause of death

\begin{tabular}{|c|c|c|c|c|c|}
\hline \multirow[b]{3}{*}{ Region/sub-region } & \multicolumn{5}{|c|}{ Attributable years of life lost (000 s) } \\
\hline & \multicolumn{2}{|c|}{$\begin{array}{c}\text { Infants } \\
<6 \text { months of age }\end{array}$} & \multicolumn{2}{|c|}{$\begin{array}{c}\text { Infants } \\
6-11 \text { months of } \\
\text { age }\end{array}$} & \multirow{2}{*}{$\begin{array}{c}\text { Children } \\
12-23 \text { months of age } \\
\text { All causes }\end{array}$} \\
\hline & DD & LRTI & $\mathrm{DD}$ & LRTI & \\
\hline Africa & 15834 & 20541 & 617 & 587 & 8477 \\
\hline Eastern* & 5478 & 9107 & 223 & 190 & 2644 \\
\hline Middle & 2403 & 2871 & 90 & 51 & 1462 \\
\hline Northern* & 1433 & 1582 & 100 & 142 & 513 \\
\hline Southern & 597 & 189 & 51 & 22 & 320 \\
\hline Western & 5923 & 6792 & 153 & 182 & 3539 \\
\hline Asia (excluding Japan) & 28980 & 31098 & 1070 & 1371 & 4576 \\
\hline Eastern* & 2893 & 2866 & 188 & 200 & $626 \ddagger$ \\
\hline South-Central & 21416 & 24533 & 520 & 733 & 2736 \\
\hline South-Eastern & 3085 & 1853 & 265 & 254 & 730 \\
\hline Western* & 1586 & 1845 & 97 & 184 & 483 \\
\hline Latin America and the Caribbean & 1682 & 1459 & 179 & 190 & 569 \\
\hline Caribbean* & 232 & 178 & 20 & 27 & 108 \\
\hline Central America & 366 & 461 & 42 & 52 & 165 \\
\hline South America & 1084 & 819 & 117 & 110 & 296 \\
\hline Developing countries $†$ & 46496 & 53097 & 1866 & 2148 & 13622 \\
\hline
\end{tabular}

DD - diarrhoeal disease; LRTI - lower respiratory tract infection.

${ }^{*}$ A small number of developing countries were omitted as they are not member countries of the World Health Organization and basic demographic and epidemiological data were not available: Reunion (Eastern Africa); Western Sahara (Northern Africa); Hong Kong Special Administrative Region and Macau (Eastern Asia); Gaza Strip (Western Asia); Guadeloupe, Martinique, Netherlands Antilles and Puerto Rico (Caribbean).

†The United Nations region Oceania (including the developing countries Guam, Fiji, French Polynesia, New Caledonia, Papua New Guinea, Samoa, Solomon Islands and Vanuatu) was omitted as exposure data were not available for these countries.

$\ddagger$ Since exposure data for Eastern Asia were not available for the second year of life, the estimate of years of life lost is based on the regional average attributable fraction for the age group.

Table 6 Offsetting deaths and years of life lost potentially caused by mother-to-child transmission of HIV through indiscriminate breast-feeding, by sub-region. These estimates provide an upper bound on the offsetting outcomes potentially caused by full compliance with international infant feeding recommendations

\begin{tabular}{lcc}
\hline Region/sub-region & $\begin{array}{c}\text { Offsetting } \\
\text { deaths }(000 \mathrm{~s})^{*}\end{array}$ & $\begin{array}{c}\text { Offsetting years of } \\
\text { life lost }(000 \mathrm{~s})^{*}\end{array}$ \\
\hline Africa & 208.6 & 16240 \\
Eastern & 106.1 & 8255 \\
Middle & 17.6 & 1373 \\
Northern & 2.8 & 218 \\
Southern & 43.7 & 3401 \\
Western & 38.5 & 2994 \\
Asia (excluding Japan) & 31.7 & 2465 \\
Eastern & 3.1 & 239 \\
South-Central & 24.4 & 1898 \\
South-Eastern & 4.2 & 329 \\
Western & - & - \\
Latin America & 1.8 & 138 \\
and the Caribbean & - & - \\
Caribbean & - & 138 \\
Central America & 1.8 & 18842 \\
South America & 242.1 & \\
Developing countries & &
\end{tabular}

${ }^{*}$ Analysed for 32 selected high-prevalence countries in the developing world: Burundi, Ethiopia, Kenya, Malawi, Mozambique, Rwanda, Uganda United Republic of Tanzania, Zambia, Zimbabwe (Eastern Africa); Angola Cameroon, Central African Republic, Democratic Republic of the Congo (Middle Africa); Sudan (Northern Africa); Botswana, Lesotho, Namibia, South Africa, Swaziland (Southern Africa); Burkina Faso, Côte d'Ivoire, Ghana, Guinea, Nigeria (Western Africa); China (Eastern Asia); India (South-Central Asia); Indonesia, Myanmar, Thailand, Vietnam (South-Eastern Asia); Haiti (Caribbean). blood pressure (56 million years) and cholesterol (35 million years) jointly account for 91 million years of life lost ${ }^{1}$. The change in the ranking of risk factors when compared with different outcome measures is due to the fact that deaths caused by suboptimal breast-feeding occur at earlier ages than those attributable to other risk factors.

Previously, we estimated that 52000 infant deaths due to diarrhoeal disease and lower respiratory tract infections in Latin America and the Caribbean were attributable to suboptimal breast-feeding ${ }^{30}$. Our present estimate for the same region, ages and causes is 43000 deaths, lower by $18 \%$ but within the uncertainty interval of the former estimate (31 000-73000). The difference can be explained by the fact that the relative risks used here are lower.

Our estimate of childhood attributable deaths (1.45 million) appears to be higher than that published by the Bellagio Child Survival Group (1.3 million). However, as we include deaths during the second year of life and do not restrict the analysis to 42 countries $^{3}$, our total should be higher. Comparing only attributable infant deaths, our estimate (1.28 million), which does not account for deaths potentially caused by mother-to-child transmission of HIV, is lower by 20000 deaths than the figure published by the Bellagio group. However, before accounting for the offsetting effects of HIV/AIDS, their figure is 1.5 million deaths (i.e. $17 \%$ higher than our corresponding estimate). It is difficult to identify the reasons for this difference since 
the data sources and methods used by the Bellagio group to analyse breast-feeding are not publicly available ${ }^{3}$.

\section{Offsetting outcomes}

Estimates of offsetting outcomes are sensitive to the estimated probability of HIV transmission in breastfeeding children of infected mothers, which could be as much as 33\% higher or lower than the figure used here while still consistent with available evidence ${ }^{15}$. Offsetting outcomes for individual sub-regions will also be sensitive to estimates of HIV prevalence among women of childbearing age ${ }^{28}$. Furthermore, while pooled data from developed countries show $70 \%$ survival at 15 -year followup for seroconverters aged $<5$ years ${ }^{29}$, corresponding values for developing countries are probably much lower, and we arbitrarily assumed survival to age 5 years.

On the other hand, assuming a homogeneous risk of vertical transmission by breast-feeding status may overstate offsetting deaths ${ }^{31}$. In addition, although WHO has estimated that 1.6 million babies are born each year to HIV-positive mothers ${ }^{15}$, the independent-risk model we use here predicts that nearly 2 million babies are born annually to HIV-positive mothers in just 32 highprevalence countries; in other words, possibly a substantial overestimate due to not accounting for the effect of seropositivity on fertility. Moreover, estimating vertical HIV transmission with cross-sectional breast-feeding prevalences such as those used here ${ }^{6}$ probably results in overestimates; nevertheless, since infants of infected mothers who breast-feed for less than 1 year are presumably exposed to some risk, we assumed all such infants face the same risk of HIV transmission as those who breast-feed for one full year.

Substantial inter-regional heterogeneity in the relative magnitude of the benefits and harms of indiscriminate breast-feeding underscores that this important child-health intervention requires the sort of individual- and settingspecific assessment recommended by $\mathrm{WHO}^{13}$. Moreover, an ecological analysis like that reported here cannot precisely estimate the fatal outcomes that could be offset by HIV infection for the very reason that recommended practice depends on the mother's HIV status and other individual- and setting-specific factors.

Offsetting outcomes, however, establish an upper bound to fatal outcomes attributable to breast-feeding by HIV-positive mothers. Notably, even in the hypothetical case of breast-feeding without regard to HIV status, the offsetting outcomes would not alter the importance of suboptimal breast-feeding as a global risk factor. Without the possibility of being more precise, the estimate of fatal childhood outcomes attributable to non-compliance with international breast-feeding recommendations lies in the range 1.21-1.45 million deaths (98-117 million years of life lost). The lower bound of this range represents a potential reduction in the global benefit of breast-feeding of nearly one-fifth (19\%) compared with widely reported estimates of the number of deaths avoidable by improved breast-feeding prior to the explosion of the AIDS pandemic in Africa ${ }^{32,33}$.

\section{Multiple causality}

Recognising the multiple causality of outcomes, double counting of deaths due to unsafe water, sanitation and hygiene and those due to suboptimal breast-feeding (both contributing to diarrhoeal disease), between suboptimal breast-feeding and underweight (both contributing to diarrhoeal disease and all-cause deaths in the second year of life), or between suboptimal breast-feeding and indoor air quality (both contributing to lower respiratory tract infections), cannot be excluded ${ }^{17}$. The synergistic effect of selected childhood diseases and risk factors has moreover been highlighted ${ }^{2}$.

\section{Confounding and measurement error}

As mothers in developing countries who breast-feed their babies tend to be poorer than those who do not, residual confounding by socio-economic status could result in underestimates of the risk of suboptimal breast-feeding due to clustering of common risk factors with poverty. However, other potential confounding factors could lead to overestimates: since babies born with higher birth weights are more likely to breast-feed, mothers' failure to breast-feed underweight babies (i.e. with higher risk of mortality) may result in 'selection bias'.

One may further argue that, while our risk estimates are calculated relative to a baseline of "predominant breastfeeding', we measure the prevalence of unexposed in terms of exclusive breast-feeding. However, we have argued in other work ${ }^{6}$, on the basis of both internal and external validity criteria, that infants reported in surveys as exclusively breast-fed typically include a notably high proportion (about 15\%) who are receiving other liquids or even solid foods. We believe it is consequently unlikely that the nominal exposure data derived from nationally representative surveys, on the one hand, and from epidemiological studies that form the basis of the estimates of risk of suboptimal breast-feeding, on the other, are inherently comparable despite their use of similar terms to describe breast-feeding status. On balance, therefore, assessment of the existence or net effect of bias due to confounding or measurement error is uncertain.

\section{Implications for developed countries}

As childhood deaths due to diarrhoeal disease and lower respiratory tract infections are very rare in developed countries, and second-year childhood deaths even $\operatorname{rarer}^{23,24,26}$, the present study is confined to developing countries. However, if outcomes were defined to include breast-feeding-attributable morbidity, developed and developing countries alike would have a substantial attributable burden of disease ${ }^{34-36}$. 


\section{Conclusions}

The age distribution of attributable outcomes reinforces the importance of emphasising exclusive breast-feeding for infants aged $\leq 6$ months. The substantial benefits of continued breast-feeding in the second year of life, moreover, highlight the importance of this neglected aspect of infant-and-child feeding recommendations.

The size of the gap between practice and recommendations is striking, especially considering that breastfeeding involves no out-of-pocket costs, that there exists universal consensus on best practices, and that implementing current international recommendations could save between 1.21 and 1.45 million lives (between 98 and 117 million years of life) among children in the developing world each year. Although the HIV/AIDS pandemic has substantially mitigated the benefits of universal (i.e. indiscriminate) breast-feeding, especially in parts of Africa, full compliance with current international breast-feeding recommendations remains one of the most important child health goals. Moreover, breast-feeding is arguably cheaper and more readily implementable than interventions such as improvements in water, sanitation and hygiene, or in general nutritional status, since unlike so many interventions the principal barriers to improved breast-feeding are not to be found in the direct monetary costs of delivery.

Nevertheless, breast-feeding, especially exclusive breast-feeding, imposes a time and energy cost on the mother, and may also have important indirect costs, such as the inability of breast-feeding mothers to participate in the wage-earning workforce. Notwithstanding, virtually all mothers can breast-feed provided they have accurate information and support within their families and communities and from the health system. Recent findings from two experimental studies ${ }^{37,38}$ and one quasiexperimental one ${ }^{39}$ demonstrate that breast-feeding counselling given in hospitals and in the community is a cost-effective way of increasing exclusive breast-feeding. A similar conclusion was reached by a systematic review of the effects of breast-feeding support ${ }^{40}$.

However, implementation of large-scale breast-feeding counselling programmes demands substantial resources and political commitment. Ideally, breast-feeding support would be provided as an integral part of routine health services for mothers. This implies the need to train health workers, lay and peer counsellors and certified lactation consultants who can help build mothers' confidence, improve feeding technique and prevent or resolve problems. Similarly, women in paid employment require minimum enabling conditions to prolong the duration of exclusive breast-feeding, such as paid maternity leave, part-time work arrangements, on-site nurseries, facilities for expressing and storing breast milk, and breast-feeding breaks.

A remaining challenge is to understand better the causes that determine the practice of exclusive breast-feeding in different settings. These include national breast-feeding policies; socio-economic and cultural factors such as medical attitudes, commercial advertising, family pressures, maternal work demands, women's employment legislation and maternal beliefs; biological factors such as infant's size, sex, growth rate, development, interest/ desire and appetite, and maternal lactation capacity; and the local epidemiology of HIV/AIDS.

\section{Acknowledgements}

The views expressed are solely those of the authors and do not necessarily reflect the decisions or the stated policy of the World Health Organization. We are grateful to Shams Arifeen for reanalysing the data from Bangladesh and to Cesar G Victora for guidance throughout the course of the research.

Competing interests: None declared.

Authors' contributions: J.A.L. and A.P.B. designed the study, analysed the data and results and drafted the manuscript. A.J.D.B. designed and interpreted the statistical methods used to reanalyse risk in the data from the Brazilian study. M.d.O. drafted key manuscript sections and participated in the interpretation of data and results. All authors revised and approved the final manuscript.

\section{References}

1 World Health Organization (WHO). The World Health Report 2002. Reducing Risks, Promoting Healthy Life. Geneva: WHO, 2002.

2 Black RE, Morris SS, Bryce J. Where and why are 10 million children dying every year? Lancet 2003; 361: 2226-34.

3 Jones G, Steketee RW, Black RE, Bhutta ZA, Morris SS. How many child deaths can we prevent this year? Lancet 2003; 362: $65-71$.

4 Ezzati M, Lopez AD, Rodgers A, Vander Hoorn S, Murray CJ. Comparative Risk Assessment Collaborating Group. Selected major risk factors and global and regional burden of disease. Lancet 2002; 360: 1347-60.

5 Ezzati M, Vander Hoorn S, Rodgers A, Lopez AD, Mathers CD, Murray CJ. Estimates of global and regional potential health gains from reducing multiple major risk factors. Lancet 2003; 361: 271-80.

6 Lauer JA, Betrán AP, Victora CG, de Onis M, Barros AJ. Breastfeeding patterns and exposure to suboptimal breastfeeding among children in developing countries: review and analysis of nationally representative surveys. BMC Medicine 2004; 2: 26.

7 WHO Collaborative Study Team on the Role of Breastfeeding on the Prevention of Infant Mortality. Effect of breastfeeding on infant and child mortality due to infectious diseases in less developed countries: a pooled analysis. Lancet 2000; 355: 451-5.

8 Brown KH, Black RE, Lopez de Romaña G, Creed de Kanashiro H. Infant feeding practices and their relationship with diarrhoeal and other diseases in Huascar (Lima), Peru. Pediatrics 1989; 83: 31-40.

9 Victora CG, Vaughan JP, Lombardi C, Fuchs SMC, Gigante LP, Smith PG, et al. Evidence for protection by breast-feeding 
against infant deaths from infectious diseases in Brazil. Lancet 1987; 2: 319-22.

10 Hanson LA. Breast-feeding as a protection against gastroenteritis and other infections. Acta Paediatrica Scandinavica 1985; 74: 641-2.

11 Arifeen SE, Black RE, Antelman G, Baqui AH, Caulfield LE, Becker S. Exclusive breastfeeding reduces acute respiratory infection and diarrhea deaths among infants in Dhaka slums. Pediatrics 2001; 108: E67.

12 Kramer MS, Kakuma R. The Optimal Duration of Exclusive Breastfeeding. A Systematic Review. WHO/NHD/01.08 Geneva: World Health Organization, 2002.

13 World Health Organization (WHO). Infant and young child nutrition. Resolution WHA54.2, Fifty-fourth World Health Assembly. Geneva: WHO, 2001. Also available at http://www.who.int/gb/ebwha/pdf_files/WHA54/ea54r2. pdf. Accessed 4 December 2003.

14 World Health Organization (WHO). The Optimal Duration of Exclusive Breastfeeding. Report of an Expert Consultation. WHO/NHD/01.09. Geneva: WHO, 2002, Geneva, 28-30 March 2001.

15 World Health Organization (WHO). Global Strategy for Infant and Young Child Feeding. Geneva: WHO, 2003.

16 Newell ML. Prevention of mother-to-child transmission of HIV: challenges for the current decade. Bulletin of the World Health Organization 2001; 79: 1138-44.

17 Murray CJ, Ezzati M, Lopez AD, Rodgers A, Vander Hoorn S. Comparative quantification of health risks: conceptual framework and methodological issues. Population Health Metrics 2003; 1: 1 .

18 Rothman KJ, Greenland S. Modern Epidemiology. Philadelphia, PA: Lippincott Williams and Wilkins, 1998.

19 Bradburn MJ, Deeks JJ, Altman DG. Stata technical bulletin 44 (sbe24) [online], 8 January 2002. Available at http://www. stata.com/products/stb/journals/stb44.html. Accessed 4 December 2003.

20 Yoon PW, Black RE, Moulton LH, Becker S. Effect of not breastfeeding on the risk of diarrheal and respiratory mortality in children under 2 years of age in Metro Cebu, The Philippines. American Journal of Epidemiology 1996; 143: 1142-8.

21 Hanson LA, Ashraf R, Karlber J, Lindbland BS, Jalil F. Breast feeding is a natural contraceptive and prevents disease and death in infants, linking infant mortality and birth rates. Acta Paediatrica 1994; 83: 3-6.

22 United Nations (UN). World Population Prospects. The 2000 Revision. New York: UN Department of Economic and Social Affairs, Population Division, 2001.

23 Murray CJ, Lopez AD, Mathers CD, Stein S. The Global Burden of Disease 2000 Project: Aims, Methods and Data Sources. GPE Discussion Paper No. 36. Geneva: World Health Organization, 2001.

24 Mathers CD, Stein S, Ma Fat D, Rao C, Inoue M, Tomijima N, et al. Global Burden of Disease 2000: Version 2 Methods and Results. GPE Discussion Paper No. 50. Geneva: World Health Organization, 2002.

25 World Health Organization (WHO). The World Health Report 2003. Shaping the Future. Geneva: WHO, 2003.
26 Lopez AD, Ahmad OB, Guillot M, Inoue M, Ferguson BD, Salomon JA. Life Tables for 191 Countries for 2000: Data, Methods, Results. GPE Discussion Paper No. 40. Geneva: World Health Organization, 2001.

27 Kirkwood BR, Gove S, Rogers S, Lob-Levyt J, Arthur P, Campbell H. Potential interventions for the prevention of childhood pneumonia in developing countries: a systematic review. Bulletin of the World Health Organization 1995; 73 : $793-8$.

28 United Nations Children's Fund. Information by country [online], 2003. Available at http://www.unicef.org/infobycountry/. Accessed 4 December 2003.

29 Collaborative Group on AIDS Incubation and HIV Survival including the CASCADE EU Concerted Action. Time from HIV-1 seroconversion to AIDS and death before widespread use of highly-active antiretroviral therapy: a collaborative reanalysis. Lancet 2000; 355: 1131-7.

30 Betrán AP, de Onis M, Lauer JA, Villar J. Ecological study of effects of breast feeding on infant mortality in Latin America. British Medical Journal 2001; 323: 303-6.

31 Coutsoudis A, Pillay K, Spooner E, Kuhn L, Coovadia HM. Influence of infant-feeding patterns on early mother-to-child transmission of HIV-1 in Durban, South Africa: a prospective cohort study. Lancet 1999; 354: 471-6.

32 World Health Organization (WHO). Infant and Young Child Nutrition (Progress and Evaluation Report; and Status of Implementation of the International Code of Marketing of Breast-milk Substitutes): Report by the Director-General. Document EB/9317. Geneva: WHO, 2001.

33 Walker ARP, Adam FI. Breast-feeding in sub-Saharan Africa: outlook for 2000. Public Health Nutrition 2000; 3: 285-92.

34 Silfverdal SA. Protective effect of breastfeeding on invasive Haemophilus influenzae infection: a case-control study in Swedish preschool children. International Journal of Epidemiology 1997; 26: 443-50.

35 Levine OS, Farley M, Harrison LH, Lefkowitz L, McGeer A, Schwartz B. Risk factors for invasive pneumococcal disease in children: a population-based case-control study in North America. Pediatrics 1999; 103: E28.

36 Nafstad P. Breastfeeding, maternal smoking and lower respiratory tract infections. European Respiratory Journal 1996; 9: 2623-9.

37 Morrow AL, Guerrero ML, Shults J, Calva JJ, Lutter C, Bravo J, et al. Efficacy of home-based peer counselling to promote exclusive breastfeeding: a randomised controlled trial. Lancet 1999; 353: 1226-31.

38 Haider R, Ashworth A, Kabir I, Huttly SR. Effect of community-based peer counsellors on exclusive breastfeeding practices in Dhaka, Bangladesh: a randomised controlled trial. Lancet 2000; 356: 1643-7.

39 Lutter CK, Perez Escamilla R, Segall A, Sanghvi T, Teruya K, Wickham C. The effectiveness of a hospital based program to promote exclusive breastfeeding among low income women in Brazil. American Journal of Public Health 1997; 87: 659-63.

40 Sikorski J, Renfrew MJ, Pindoria, S, Wade A. Support for breastfeeding mothers. Cochrane Database Syst Rev 2002; (1): CD001141 


\section{Appendix - Supplementary material}

Table A1 Odds ratios (OR) and 95\% confidence intervals (Cl) of suboptimal breast-feeding and selected control variables for infant mortality due to lower respiratory tract infections among infants $0-5$ months of age

\begin{tabular}{|c|c|c|}
\hline Variable & OR $(95 \% \mathrm{Cl})$ & $P$-value \\
\hline \multicolumn{3}{|l|}{ Level 1} \\
\hline Father not living with child & $2.0(1.1-3.6)$ & 0.03 \\
\hline Income per capita & & 0.02 \\
\hline 1st quartile & - & \\
\hline 2nd quartile & $0.7(0.4-1.3)$ & \\
\hline 3rd quartile & $0.9(0.5-1.6)$ & \\
\hline 4th quartile & $0.4(0.2-0.7)$ & \\
\hline Infant's age (months) & & 0.001 \\
\hline $0-1$ & - & \\
\hline $2-3$ & $3.2(1.7-6.1)$ & \\
\hline $4-5$ & $2.4(1.2-4.7)$ & \\
\hline \multicolumn{3}{|l|}{ Level 3} \\
\hline No. of previous pregnancies & & 0.06 \\
\hline 0 & - & \\
\hline 1 & $0.7(0.3-1.5)$ & \\
\hline $2-3$ & $1.7(0.8-3.5)$ & \\
\hline $4+$ & $2.2(0.9-5.7)$ & \\
\hline Mother's age (years) & & 0.13 \\
\hline $14-19$ & - & \\
\hline $20-24$ & $0.6(0.3-1.1)$ & \\
\hline $25-29$ & $0.4(0.2-1.0)$ & \\
\hline $30-45$ & $0.4(0.1-0.9)$ & \\
\hline \multicolumn{3}{|l|}{ Level 4} \\
\hline Birth weight (g) & & 0.15 \\
\hline$<2500$ & $1.9(0.9-4.3)$ & \\
\hline $2500-2999$ & $1.5(0.9-2.5)$ & \\
\hline $3000+$ & - & \\
\hline Breast-feeding mode & & $<0.001$ \\
\hline Predominant/exclusive & - & \\
\hline Partial & $2.8(1.4-5.8)$ & \\
\hline None & $4.7(2.4-9.1)$ & \\
\hline
\end{tabular}

Table A2 Odds ratios (OR) and 95\% confidence intervals (Cl) of suboptimal breast-feeding and selected control variables for infant mortality due to lower respiratory tract infections among infants $6-11$ months of age

\begin{tabular}{lcc}
\hline Variable & OR $(95 \% \mathrm{Cl})$ & $P$-value \\
\hline $\begin{array}{l}\text { Level 1 } \\
\text { Mother's education (years) }\end{array}$ & & \\
$\quad 0$ & $3.1(1.1-9.1)$ & 0.13 \\
$1-4$ & $1.4(0.6-3.3)$ & \\
$5+$ & - & \\
$\begin{array}{l}\text { Household head employed } \\
\text { Infant's age (months) }\end{array}$ & $0.5(0.2-1.4)$ & 0.20 \\
$\quad 6-8$ & - & 0.04 \\
$9-11$ & $0.4(0.2-1.0)$ & \\
Level 4 & & \\
Birth weight (g) & & \\
$\quad<2500$ & $5.4(1.8-15.8)$ & \\
$\quad 2500-2999$ & $2.7(1.1-6.6)$ & \\
$\quad 3000+$ & $0.2(0.0-1.9)$ & 0.10 \\
Low Apgar score at birth & $2.8(1.0-7.7)$ & 0.03 \\
Not breast-fed &
\end{tabular}

Table A3 Odds ratios (OR) and 95\% confidence interval (Cl) of suboptimal breast-feeding and selected control variables for infant mortality due to diarrhoeal disease among infants $0-5$ months of age

\begin{tabular}{|c|c|c|}
\hline Variable & OR $(95 \% \mathrm{Cl})$ & $P$-value \\
\hline \multicolumn{3}{|l|}{ Level 1} \\
\hline Mother's education (years) & & 0.06 \\
\hline 0 & $2.7(0.9-8.3)$ & \\
\hline $1-4$ & $2.7(1.0-7.2)$ & \\
\hline $5-8$ & $1.7(0.6-4.6)$ & \\
\hline $9+$ & - & \\
\hline \multicolumn{2}{|l|}{ Mother's ethnicity } & 0.10 \\
\hline White & - & \\
\hline Mixed race & $1.4(0.8-2.4)$ & \\
\hline Black & $1.7(1.0-3.0)$ & \\
\hline \multicolumn{2}{|l|}{ Infant's age (months) } & $<0.001$ \\
\hline $0-1$ & - & \\
\hline $2-3$ & $2.9(1.6-5.2)$ & \\
\hline $4-5$ & $2.7(1.4-5.1)$ & \\
\hline \multicolumn{3}{|l|}{ Level 2} \\
\hline Household has no flush toilet & $1.7(1.1-2.7)$ & 0.02 \\
\hline \multicolumn{3}{|l|}{ Level 3} \\
\hline \multicolumn{2}{|l|}{ Birth interval (months) } & 0.002 \\
\hline First child & $2.8(1.5-5.5)$ & \\
\hline $9-20$ & $1.6(0.9-3.1)$ & \\
\hline $21-50$ & $0.8(0.3-2.0)$ & \\
\hline $51+$ & - & \\
\hline \multicolumn{2}{|l|}{ Mother's age (years) } & 0.20 \\
\hline $14-19$ & - & \\
\hline $20-24$ & $1.5(0.8-2.9)$ & \\
\hline $25-29$ & $0.8(0.4-1.7)$ & \\
\hline $30-45$ & $1.0(0.4-2.1)$ & \\
\hline \multicolumn{3}{|l|}{ Level 4} \\
\hline \multicolumn{2}{|l|}{ Birth weight (g) } & 0.03 \\
\hline$<2500$ & $2.7(1.3-5.8)$ & \\
\hline $2500-2999$ & $1.4(0.8-2.5)$ & \\
\hline \multicolumn{3}{|l|}{$3000+$} \\
\hline Birth not in hospital & $3.7(1.3-10.2)$ & 0.01 \\
\hline Delivery by Caesarian section & $0.6(0.2-1.3)$ & 0.10 \\
\hline \multicolumn{2}{|l|}{ No. of antenatal care visits } & 0.02 \\
\hline 0 & - & \\
\hline $1-4$ & $0.9(0.5-1.8)$ & \\
\hline $5-8$ & $0.5(0.2-1.0)$ & \\
\hline $9+$ & $0.4(0.2-0.9)$ & \\
\hline \multicolumn{3}{|l|}{ Breast-feeding mode } \\
\hline Predominant/exclusive & - & $<0.001$ \\
\hline Partial & $2.4(1.1-5.2)$ & \\
\hline None & $7.3(3.7-14.4)$ & \\
\hline
\end{tabular}


Table A4 Odds ratios (OR) and 95\% confidence intervals (Cl) of suboptimal breast-feeding and selected control variables for infant mortality due to diarrhoeal disease among infants $6-11$ months of age

\begin{tabular}{|c|c|c|}
\hline Variable & OR $(95 \% \mathrm{Cl})$ & $P$-value \\
\hline \multicolumn{3}{|l|}{ Level 1} \\
\hline Income per capita & & 0.11 \\
\hline 1st quartile & - & \\
\hline 2nd quartile & $0.7(0.3-1.7)$ & \\
\hline 3rd quartile & $0.8(0.3-1.8)$ & \\
\hline 4th quartile & $0.3(0.1-0.9)$ & \\
\hline Male infant & $1.5(0.8-2.9)$ & 0.19 \\
\hline Infant's age(months) & & $<0.001$ \\
\hline $6-8$ & - & \\
\hline $9-11$ & $0.2(0.1-0.5)$ & \\
\hline \multicolumn{3}{|l|}{ Level 2} \\
\hline Household has piped water & $0.5(0.2-1.0)$ & 0.04 \\
\hline No. of persons per sleeping room & & 0.20 \\
\hline $1-2$ & - & \\
\hline $3-5$ & $2.5(0.7-9.1)$ & \\
\hline $6+$ & $3.9(0.9-17.2)$ & \\
\hline \multicolumn{3}{|l|}{ Level 3} \\
\hline No. of previous pregnancies & & 0.10 \\
\hline 0 & - & \\
\hline 1 & $4.2(1.4-12.4)$ & \\
\hline $2-3$ & $1.4(0.4-4.3)$ & \\
\hline $4+$ & $2.2(0.6-8.8)$ & \\
\hline Mother's age (years) & & 0.30 \\
\hline $14-19$ & - & \\
\hline $20-24$ & $0.4(0.2-1.2)$ & \\
\hline $25-29$ & $0.5(0.1-1.5)$ & \\
\hline $30-45$ & $0.2(0.0-0.8)$ & \\
\hline Not breast-fed & $2.5(1.1-5.7)$ & 0.02 \\
\hline
\end{tabular}

